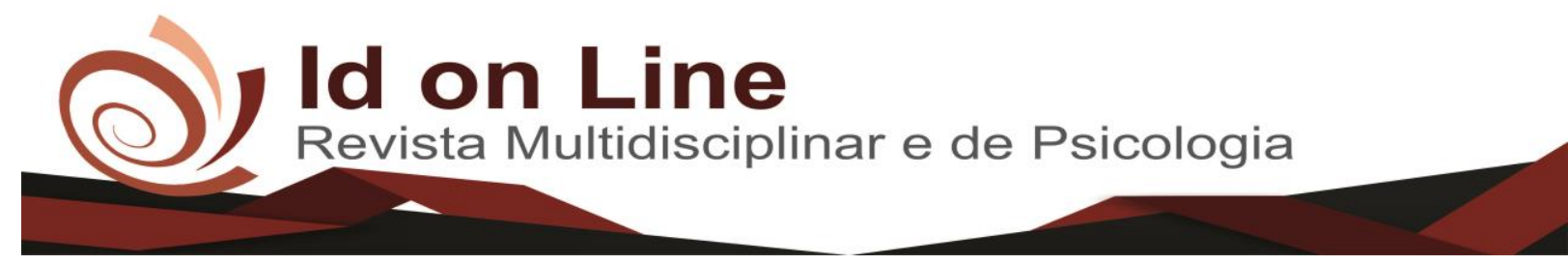

Artigo

\title{
Análise Físico-Química da Qualidade da Água do Rio Pardo no Município de Cândido Sales - BA
}

\author{
Wadson Rodrigo Ferreira de Almeida ${ }^{1}$; Flavio Mendes de Souza ${ }^{2}$
}

\begin{abstract}
Resumo: Entendendo a importância da água para o consumo humano, e os problemas fisiopatológicos que uma água não tratada pode ocasionar, a presente pesquisa faz uma análise, específica, da água do Rio Pardo no município de Cândido Sales - BA. As coletas das amostras foram feitas em três fases, entre os meses de agosto e novembro do ano de 2018, com o intuito de acompanhar a variação pluvial que varia do mês de maior seca (agosto) ao inicio das chuvas (novembro). Segundo as análises realizadas, os valores de pH, Resistividade elétrica, TDS e Turbidez se encontram dentro dos parâmetros exigidos pela legislação vigente. Não apresentando variações consideráveis entre as amostras. Apesar do despejo inapropriado de sedimentos no rio, em relação aos parâmetros físico-químicos, não houve alterações consideráveis na integridade da água, o que não necessariamente comprova que está apta para o consumo humano, pois não está descartada a possibilidade de contaminação ou ocorrência de outros problemas de saúde nessa população alvo. Para tal comprovação ainda seria necessária à análise do solo de margem, para determinar se esses problemas são de ocorrência periódica ou permanente, podendo ocorrer numa futura pesquisa.
\end{abstract}

Palavras-chave: análise de água, parâmetros físico-químicos, qualidade da água, esgoto doméstico.

\section{Physical-Chemical Analysis of the Water Quality of Rio Pardo in the Municipality of Cândido Sales in Bahia}

\begin{abstract}
Understanding the importance of water for human consumption and the pathophysiological problems that an untreated water can cause, the present research makes a specific analysis of the water of the Rio Pardo in the municipality of Cândido Sales - BA. The samples were collected in three phases between August and November of the year 2018, in order to follow the rainfall variation that varies from the month of greatest drought (August) to the beginning of the rains (November). According to the analysis, the values of $\mathrm{pH}$, Electrical Resistivity, TDS and Turbidity are within the parameters required by current legislation. There were no significant variations between samples. Despite the inadequate disposal of sediments in the river, in relation to the physicochemical parameters, there were no significant alterations in the integrity of the water, which does not necessarily prove that it is fit for human consumption, since it is not ruled out the possibility of contamination or occurrence of other health problems in this target population. For such proof it would still be necessary to analyze the margin soil, to determine if these problems are of periodic or permanent occurrence, and may occur in a future research.
\end{abstract}

Key words: water analysis, physical-chemical parameters, water quality, domestic sewage.

\footnotetext{
${ }^{1}$ Curso de Farmácia. Faculdade Independente do Nordeste - FAINOR, Brasil. Contato: wrodrigoalmeida@ gmail.com;

${ }^{2}$ Mestrado em Química pela Universidade Estadual do Sudoeste da Bahia, Brasil. Professor da Faculdade Independente do Nordeste - FAINOR, Brasil. Contato: flaviomendes@fainor.com.br
} 


\section{Introdução}

A água é de vital importância para a vida no planeta, sendo que praticamente todo organismo vivo depende de um suprimento mínimo, considerando que todas as reações fisiológicas acontecem em meio a soluções aquosas. Segundo Santos, 2007, além disso, há outras funções de grande importância para a água, como: irrigação, geração de energia, navegação, limpeza de praticamente qualquer tipo de material são outras utilidades de grande importância da água.

Apesar dos benefícios e utilidades, a água precisa estar em suas conformidades para servir aos interesses humanos. Porém, a própria espécie humana está degradando cada vez mais esse recurso natural e abundante. O desperdício, má utilização e a contaminação dos lençóis freáticos, além do despejo de substâncias tóxicas e inorgânicas nos corpos de água, interferem diretamente na sua constituição e comprometem não só a vida aquática e costeira, mas também causam prejuízos à própria espécie humana como afirmam, SILVA e ARAÚJO (2003).

A água própria para consumo deve cumprir exigências rigorosas de qualidade. Não é de proibição o consumo de águas naturais, de rios, mananciais e poços artesianos, mas o conceito popular de que "se é natural não faz mal" está cada vez mais obsoleto devido o descarte inadequado de poluentes nas águas, que influenciam na sua integridade e de seus componentes.

Outro fator que pode contribuir para a inapropriação da água, que está presente na cidade estudada nessa pesquisa são os curtumes. Os curtumes são unidades de processamento de peles de animais, que são limpas e retiram todos os vestígios orgânicos das carcaças. Posteriormente são manufaturados em produtos de consumo da indústria têxtil, automotivo e agropecuário. Nesse processo de limpeza do couro, produtos tóxicos são amplamente utilizados para alcançarem a qualidade do produto, incluindo sulfeto de sódio e álcalis à base de mercúrio. (CUNHA; e SHIRAIWA, 2011).

Em 1999, a Organização das Nações Unidas (ONU), declara que 90\% das doenças que acometem a humanidade estão diretamente relacionadas às más condições das águas, provocada pela poluição e falta de tratamento adequado dos corpos hídricos.

Segundo o Artigo 200, parágrafos IV e VI, da Constituição Federal de 1988, é competência do Sistema Único de Saúde (SUS), a responsabilidade de fiscalizar e manter a integridade da água para consumo humano. Além disso, gerir e formular ações de saneamento básico; fiscalizar e garantir qualidade de alimentos, bebidas e garantir que esses recursos cheguem com qualidade adequada de consumo para toda a população.

A Lei Orgânica da Saúde (Lei $n^{\circ}$ 8.080/1990), em seu Artigo $6^{\circ}$, designa como responsabilidade do SUS, o ato de fiscalizar e inspecionar a água direcionada para consumo humano, incluindo a manutenção do esgotamento sanitário ligado diretamente aos cidadãos. 
Com isso, o objetivo central dessa pesquisa, é coletar os dados necessários para dar procedência à análise de qualidade da água de um trecho especifico da bacia do Rio Pardo, que passa pelo município de Cândido Sales - BA, consumida por moradores ribeirinhos que utilizam a água diretamente do rio, sem tratamento adequado pela Embasa (Empresa Baiana de Águas e Saneamento). Além disso, SOUZA (2014) acredita que o descarte irregular do lixo doméstico originado das residências diretamente nas águas do rio, pode comprometer a saúde das pessoas e até mesmo a flora e fauna aquática e costeira.

Segundo DANIEL (2011), para determinar se uma água está própria ou não para o consumo humano, não só a parte visível da água deve estar em equilíbrio, como a coloração cristalina ou isenta de materiais orgânicos, mas também fatores imperceptíveis para os olhos ou paladar humano. Os parâmetros físico-químicos são indicadores primordiais de qualidade, o desequilíbrio desses indicadores pode indicar comprometimento da água e acarretar complicações à saúde.

Os parâmetros físico-químicos que serão analisados são: Condutividade elétrica; Potencial Hidrogeniônico $(\mathrm{pH})$; Resistividade elétrica; Temperatura $\left({ }^{\circ} \mathrm{C}\right)$; Teor de sólidos dissolvidos (TDS); e Turbidez. Além de dureza total vinculada ao teor de carbonato de cálcio e teor de cloreto.

O objetivo geral deste trabalho foi analisar os aspectos físico-químicos da água do Rio Pardo consumida pela população ribeirinha do município de Cândido Sales - BA. Para isso foi necessário também:

- Determinar os parâmetros físico-químicos como: Condutividade elétrica; Potencial Hidrogeniônico $(\mathrm{pH})$; Resistividade elétrica; Temperatura $\left({ }^{\circ} \mathrm{C}\right)$; Teor de sólidos dissolvidos (TDS); e Turbidez da água do Rio Pardo. Parâmetros de dureza total, teor carbonato de cálcio e cloreto.

- Coletar amostras de água nos 5 (cinco) trechos determinados do rio em datas específicas.

- Analisar o conteúdo no laboratório, registrando seus resultados.

- Comparar os resultados seguindo os parâmetros determinados com a legislação vigente da Portaria MS nº 2.914 de 2011; Resoluções CONAMA (Ed. Especial, 2012); e Organização Mundial de Saúde (OMS).

\section{Referencial Teórico}

Segundo a Organização das Nações Unidas (ONU), o Brasil possui um potencial hídrico equivalente a $12 \%$ de toda água doce acessível do planeta. Suas bacias mais abundantes são as do Rio São Francisco, do Paraná e a Amazônica. A bacia Amazônica é considerada a mais extensa do mundo, delimitada em $60 \%$ dela fazendo parte do território brasileiro. A ONU ainda estabelece um mínimo de 
$1.700 \mathrm{~m}^{3} / \mathrm{s}$ de água por habitante por ano, no Brasil, essa marca apresenta proporções 19 vezes superior, ou seja, aproximadamente $32.300 \mathrm{~m} 3 / \mathrm{s}$.

\title{
Condutividade Elétrica
}

Quanto maior a condutividade elétrica, maior a contaminação da água. Pelo conceitual de Santos (2007, p. 22):

\begin{abstract}
A condutividade elétrica da água é determinada pela presença de substâncias dissolvidas que se dissociam em ânions e cátions. É a capacidade de a água transmitir a corrente elétrica.
\end{abstract}

A Resolução CONAMA n 357 de 2005 determina que a margem de variação dos valores medidos em relação a águas naturais pode variar de 10 a $100 \mu \mathrm{S} / \mathrm{cm}$. Águas já com presença de poluentes, se encontrarão em uma margem superior a $1.000 \mu \mathrm{S} / \mathrm{cm}$.

\section{Potencial Hidrogeniônico (pH)}

Dezotti (2008) descreve o conceito de $\mathrm{pH}$, como um "parâmetro químico que representa o equilíbrio entre íons $\mathrm{H}^{+}$e íons $\mathrm{OH}^{-"}$. O pH apresenta uma escala que varia de 1 a 14 . Em termos de classificação, quando uma substância é considerada ácida, o valor da escala é apresentado abaixo de 7 $(\mathrm{pH}<7)$; uma substância é classificada como neutra, quando o valor está em 7 ( $\mathrm{pH}=7)$, determinando que haja aproximadamente a mesma concentração de íons $\mathrm{H}^{+}$e $\mathrm{OH}^{-}$; já para determinada substância ser considerada alcalina, deve ser apresentada $\mathrm{pH}$ superior a $7(\mathrm{pH}>7)$; a variação do $\mathrm{pH}$ da água depende tanto das características naturais de origem quanto de fatores externos e substancias que podem potencialmente influenciar sua composição e por consequência, alterar o pH natural.

Segundo Soares (1999, p. 4), o valor do pH é importante, pois apresenta forte relação com o crescimento bacteriano, uma vez que para a maioria das bactérias o $\mathrm{pH}$ ótimo para seu desenvolvimento oscila entre 6,5 e 7,5

A Resolução CONAMA no 430/2011, determina que o pH dos resíduos lançados no corpo do rio, tem uma margem de tolerância de 5 a 9. No mesmo contexto a Portaria nº518/2004 do Ministério da Saúde, recomenda uma variação de pH entre 6,0 a 9,5 que seria apropriada para consumo humano.

\section{Resistividade Elétrica}

A resistividade elétrica ou eletrorresistividade é determinada pela Lei de Ohm (1825), que afirma que "a corrente que se estabelece num corpo condutor é proporcional à voltagem aplicada neste corpo". 
Orellana (1972) explica a resistividade elétrica (ou eletrorresistividade) como sendo a facilidade que uma corrente elétrica tem de atravessar um corpo. Tomando essa teoria como base, Silva (2008) aplica esse método na geofísica, que utiliza em larga escala no estudo de áreas contaminadas por resíduos sólidos, como por exemplo, na delimitação da contaminação subterrânea provenientes de aterros sanitários ou do lençol freático de um modo geral.

Gallas et al. (2005) defende que o método é efetivo e funcional, afirmando que mesmo se houver uma pequena variação ou presença de contaminantes dissolvidos nas águas do subsolo, pode influenciar consideravelmente os valores de resistividade elétrica dessa água. Tais valores, em relação à água potável, devem variar entre $2 \times 10^{1}$ e $2 \times 10^{3} \Omega \mathrm{m}$.

\title{
Temperatura $\left({ }^{\circ} \mathrm{C}\right)$
}

A temperatura é um parâmetro vital no controle da vida aquática, tendo influencia em vários parâmetros, tanto físicos quanto químicos. A temperatura da água pode ser influenciada por fatores como: altitude e latitude; estação do ano; período do dia, que está relacionada com a absorbância dos raios Ultravioleta (UV), além da própria profundidade do corpo d'agua e fluxo corrente. A temperatura,

Tem influência sobre muitas variáveis, como por exemplo, a solubilidade de gases; é de fundamental importância para os sistemas aquáticos terrestres; altas temperaturas podem causar reações adversas nos indivíduos, como a desnaturação de proteínas, enquanto baixas temperaturas aumentam a perda de calor do corpo para o meio externo, aumentando o gasto de calorias para a manutenção da temperatura corporal. (ZUMACH, 2003, p. 20).

Nesse sentido, Santos (2007, p. 22) afirma que:

\begin{abstract}
A temperatura exerce influência sobre os processos biológicos e reações químicas e bioquímicas que ocorrem na água e em outros processos, como a solubilidade dos gases dissolvidos e sais minerais. Com a elevação da temperatura da água, por exemplo, a solubilidade dos gases diminui e a dos sais minerais aumenta e este fato também exerce influência sobre o processo de crescimento microbiológico, pois cada microorganismo possui uma faixa ideal de temperatura.
\end{abstract}

Apesar disso, a Portaria nº 518/2004, não determina valores de referência para a temperatura da água. Entretanto, temperaturas abaixo de $10^{\circ} \mathrm{C}$ ou acima de $40^{\circ} \mathrm{C}$ podem causar desde desconforto ao deglutir, até queimaduras leves no sistema gástrico que poderiam acarretar problemas maiores.

\section{Teor de Sólidos Dissolvidos (TDS)}

Teor de Sólidos dissolvidos (TDS), é a quantidade de resíduos sólidos presentes na água, que muitas vezes são substâncias orgânicas provenientes de fontes naturais do próprio curso do rio e de suas 
margens. A Portaria MS nº 2914/2011, estima que o padrão para consumo humano aceitável da presença dessas substâncias na água é de até 1000 mg/L. Já a Resolução no 357 de 2005, do Ministério do MeioAmbiente, determina que o padrão indicado para consumo humano deve ser menor que $500 \mathrm{mg} / \mathrm{L}$.

\section{Turbidez}

Segundo MOTA (1995), a turbidez é representada por Unidades Nefelométrica de Turbidez (NTU), que é o parâmetro medidor de turvação de um líquido. A turvação da água, por exemplo, ocorre devido à presença de materiais em suspensão em no meio líquido, tais como material orgânico, minério insolúvel provenientes do próprio solo periférico, partículas inorgânicas derivadas de fontes externas e organismos microscópicos.

Conforme Wilson (2010), "a variação na turbidez da água pode causar interferência na vida aquática, podendo afetar a fotossíntese de plantas, além de prejudicar algumas espécies de peixes afetando diretamente a cadeia alimentar.". Segundo a Resolução CONAMA n 357/2005, os valores de turbidez para rios de classe I, não devem ultrapassar valores acima de 40 NTU. Aprile \& Siqueira (2012, p. 417) reforçam que:

Água límpida isenta de turbidez é importante quando ela se destina direta ou indiretamente ao consumo humano ou processos industriais, sendo que, turbidez acima de 5 NTU além de ser notada pelo consumidor e representar uma condição insatisfatória, dificulta o processo de desinfecção/esterilização por tratamento com radiação U.V.

\section{Dureza Total}

Segundo Santos, 2007, o termo conceitual de dureza da água, se dá principalmente pela presença dos sais metálicos dos cátions de cálcio e magnésio. Outros metais podem estar presentes na água, como: bário, estrôncio, ferro, manganês e zinco, mas estão geralmente na sua forma molecular complexa. A dureza pode ser classificada como temporária (carbonatada), com presença de carbonato de cálcio e magnésio, ou permanente (não carbonatada), quando há considerável teor de cloretos e sulfatos de magnésio.

A Organização Mundial de Saúde (OMS) classifica água conceituada, em relação à concentração de Carbonato de Cálcio $\left(\mathrm{CaCo}_{3}\right)$ como: 
Tabela 1 - Classificação da água em relação à concentração de Carbonato de Cálcio $\left(\mathrm{CaCo}_{3}\right)$, segundo a OMS.

\begin{tabular}{c|c}
\hline Dureza & Concentração de $\mathbf{C a C O}_{\mathbf{3}}$ \\
\hline Muito dura & $>180 \mathrm{mg} / \mathrm{L}$ \\
\hline Dura & 120 a $180 \mathrm{mg} / \mathrm{L}$ \\
\hline Moderadamente dura & 60 a $120 \mathrm{mg} / \mathrm{L}$ \\
\hline Macia & $<60 \mathrm{mg} / \mathrm{L}$ \\
\hline
\end{tabular}

Fonte: Organização Mundial de Saúde

Em relação ao Carbonato de Cálcio (CaCO3), a portaria no 518/2004 do Ministério da Saúde, determina uma concentração máxima de $500 \mathrm{mg} / \mathrm{L}$ permitido para água para consumo humano.

\section{Teor de Cloreto}

Os métodos mais utilizados para determinar o teor do ânion Cloreto $\left(\mathrm{Cl}^{-}\right)$em uma amostra, são: Colorimetria, Gravimetria, Potenciometria e Volumetria. Segundo (BACCAN et al, 2001, p. 230-231), o método de Mohr, do tipo Volumetria, é amplamente utilizado para determinar cloreto em solução não tamponadas ou neutras. Baseia-se na determinação direta do íon cloreto, onde o haleto é titulado com uma solução-padrão de Nitrato de Prata $\left(\mathrm{AgNo}_{3}\right)$ e como indicador, utiliza-se a solução de Cromato de Potássio $\left(\mathrm{K}_{2} \mathrm{CrO}_{4}\right)$. A Portaria n ${ }^{\circ} 1.469$ de 29 de dezembro de 2000, do Ministério da Saúde, determina que o teor máximo de cloreto permissível, em águas de abastecimento, é de $250 \mathrm{mg} / \mathrm{L} \mathrm{de} \mathrm{Cl}^{-}$.

\section{Metodologia da Pesquisa}

Essa pesquisa é classificada como pesquisa descritiva, por descrever características de uma experiência realizada através de levantamentos e estudo de campo, e quantitativa por deferir seus resultados recorrendo de uma linguagem matemática, criando relações entre variáveis e outras aplicações.

Em visita ao local, constata-se que cerca de 50 (cinquenta) famílias são abastecidas diretamente com a água das margens do Rio Pardo. A água proveniente de meios naturais nesse caso, não passa pelo tratamento da Embasa (Empresa Baiana de Águas e Saneamento) para ser adequada ao consumo humano.

Os munícipes de Cândido Sales-Ba, não consomem a água diretamente do rio. A água consumida na cidade passa pelo tratamento adequado para atender os padrões de consumo humano e sua distribuição fica a cargo da Embasa. 


\section{Características Gerais dos Locais de Amostragem}

Cândido Sales está situada a sudoeste do estado da Bahia, a 86 km de Vitória da Conquista - BA e $595 \mathrm{~km}$ da Capital Salvador - BA. Com coordenadas geográficas de 15 30'18" de latitude Sul e $41^{\circ} 14^{\prime} 20^{\prime \prime}$ longitude Oeste. Possui área de 1.617,522 $\mathrm{m}^{2}$ e altitude de $687 \mathrm{~m}$. Sua população estimada pelo IBGE em 2016 é de aproximadamente 27.918 habitantes. O clima é definido como subúmido a seco. Possui Bioma predominante de Mata Atlântica. A economia agropecuária é definida por plantio de cana-de-açúcar, feijão, mandioca, milho e derivados; criação de bovinos, caprinos e de aves galináceas.

O Rio Pardo tem sua extensão medida em aproximadamente $565 \mathrm{~km}$. Sua bacia drena área de $32.905 \mathrm{Km}^{2}$. Sua nascente está localizada entre os Municípios mineiros Montezuma, Santo Antônio do Retiro e Monte Azul (MG). A uma altitude aproximada de $880 \mathrm{~m}$. O rio segue pelo Norte do Estado de Minas Gerais (220 km) e entra no Estado da Bahia no perímetro do povoado de Porto de Santa Cruz, no município de Cândido Sales. Seguindo a diante, encontra-se um ponto de amarração de limites da Bahia com Minas Gerais: A barra do Rio Mosquito, no Rio Pardo, no lado mineiro. Depois de percorrer 345 km no Estado da Bahia, o Rio Pardo deságua no Oceano Atlântico, na praia do município de Canavieiras-Ba.

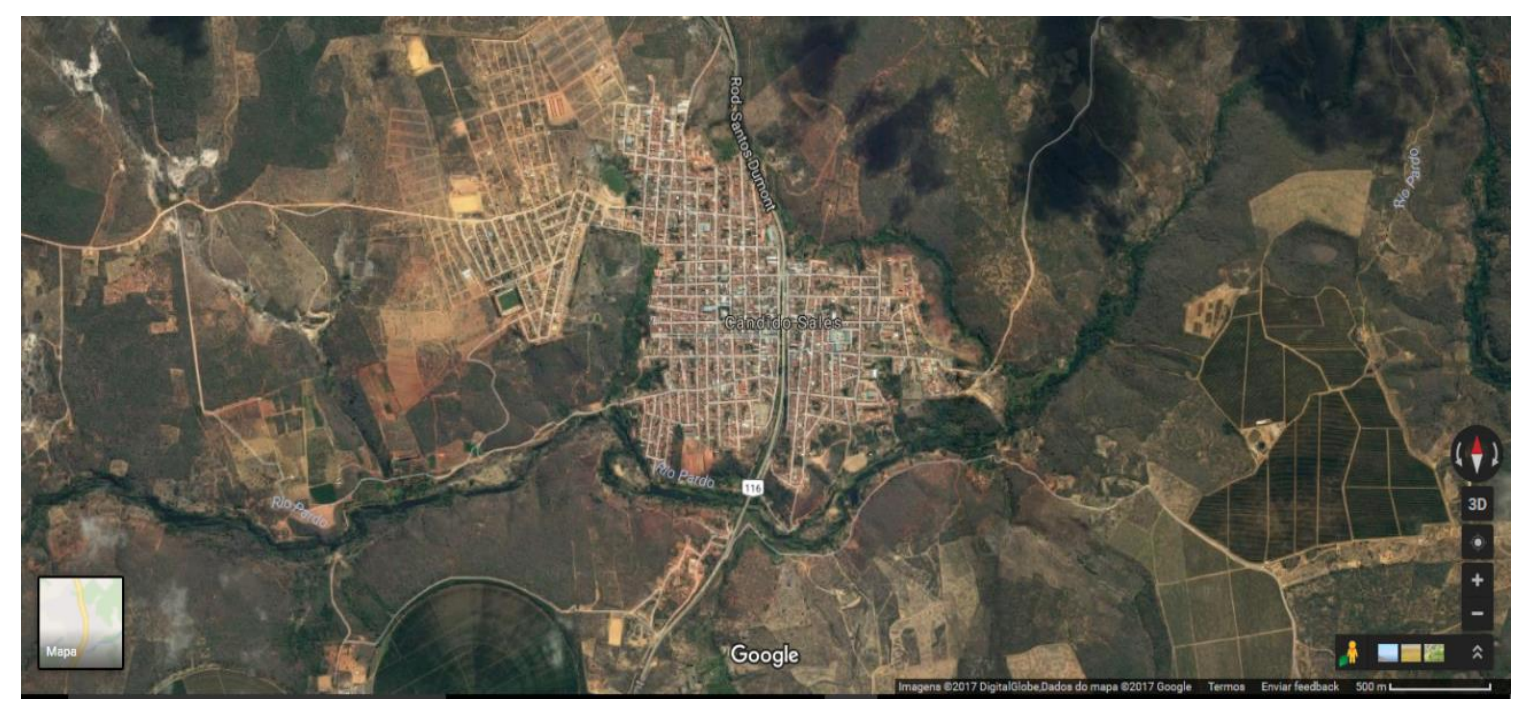

Figura 1: Município de Cândido Sales, foto de satélite** 
Tabela 1: Tabela climática de Cândido Sales - BA

\begin{tabular}{|c|c|c|c|c|c|c|c|c|c|c|c|c|}
\hline & JAN & FEV & MAR & ABR & MAI & JUN & JUL & AGO & SET & OUT & NOV & DEZ \\
\hline Temp. média $\left({ }^{\circ} \mathrm{C}\right)$ & 23.9 & 24.1 & 23.2 & 22.0 & 20.2 & 19.5 & 19.7 & 20.7 & 22.3 & 23.2 & 23.3 & 22.7 \\
\hline Temp. mínima $\left({ }^{\circ} \mathrm{C}\right)$ & 18.6 & 18.8 & 18.3 & 17.0 & 15.1 & 14.3 & 14.2 & 15.0 & 16.7 & 18.1 & 18.4 & 17.8 \\
\hline Temp. máxima $\left({ }^{\circ} \mathrm{C}\right)$ & 29.2 & 29.4 & 28.1 & 27.0 & 25.4 & 24.7 & 25.2 & 26.5 & 27.9 & 28.4 & 28.3 & 27.6 \\
\hline Temp. média $\left({ }^{\circ} \mathrm{F}\right)$ & 75.0 & 75.4 & 73.8 & 71.6 & 68.4 & 67.1 & 67.5 & 69.3 & 72.1 & 73.8 & 73.9 & 72.9 \\
\hline Temp. mínima $\left({ }^{\circ} \mathrm{F}\right)$ & 65.5 & 65.8 & 64.9 & 62.6 & 59.2 & 57.7 & 57.6 & 59.0 & 62.1 & 64.6 & 65.1 & 64.0 \\
\hline Temp. máxima $\left({ }^{\circ} \mathrm{F}\right)$ & 84.6 & 84.9 & 82.6 & 80.6 & 77.7 & 76.5 & 77.4 & 79.7 & 82.2 & 83.1 & 82.9 & 81.7 \\
\hline Chuva (mm) & 144 & 75 & 84 & 52 & 20 & 15 & 13 & 8 & 20 & 85 & 162 & 178 \\
\hline
\end{tabular}

Fonte: climate-data.org

\section{Localização Geográfica dos Pontos de Coleta}

Os dados de amostragem foram adquiridos por meio da coleta de água feita diretamente no leito do Rio Pardo. Os resultados apenas apontam possíveis malefícios à saúde, quando comparada com a literatura e legislação vigente e se forem classificadas como inadequadas para o consumo humano. Nessa pesquisa não foi necessário à coleta de dados diretamente com os consumidores dessa água.

No quadro 1, é possível observar as coordenadas geográficas e valores de altitude referente a cada ponto de coleta do percurso determinado do Rio Pardo. Para obter os dados, foi usado Aparelho GPS da marca Garmin, modelo WGS84.

Quadro 1: Coordenadas geográficas e altitude dos pontos de coleta

\begin{tabular}{|c|c|c|c|}
\hline Pontos de coleta & Coordenadas geográficas & Altitude (m) & Variação (m) \\
\hline P1 & $\begin{array}{c}\text { Latitude: }-15^{\circ} 30^{\prime} 52,68^{\prime \prime} \mathrm{S} \\
\text { Longitude: }-41^{\circ} 15^{\prime} 25,6^{\prime \prime} \mathrm{W}\end{array}$ & $620 \mathrm{~m}$ & $10 \mathrm{~m}$ \\
\hline P2 & $\begin{array}{c}\text { Latitude: }-15^{\circ} 30^{\prime} 43^{\prime \prime} \mathrm{S} \\
\text { Longitude: }-41^{\circ} 15^{\prime} 6^{\prime \prime} \mathrm{W}\end{array}$ & $623 \mathrm{~m}$ & $4 \mathrm{~m}$ \\
\hline P3 & $\begin{array}{c}\text { Latitude: }-15^{\circ} 30^{\prime} 33,80^{\prime \prime} \mathrm{S} \\
\text { Longitude: }-41^{\circ} 14^{\prime} 37,4^{\prime \prime} \mathrm{W}\end{array}$ & $609 \mathrm{~m}$ & $10 \mathrm{~m}$ \\
\hline P4 & $\begin{array}{c}\text { Latitude: }-15^{\circ} 30^{\prime} 47^{\prime \prime} \mathrm{S} \\
\text { Longitude: }-41^{\circ} 14^{\prime} 12^{\prime \prime} \mathrm{W}\end{array}$ & $607 \mathrm{~m}$ & $4 \mathrm{~m}$ \\
\hline P5 & $\begin{array}{c}\text { Latitude: }-15^{\circ} 30^{\prime} 29^{\prime \prime} \mathrm{S} \\
\text { Longitude: }-41^{\circ} 13^{\prime} 22^{\prime \prime} \mathrm{W}\end{array}$ & $592 \mathrm{~m}$ & $5 \mathrm{~m}$ \\
\hline
\end{tabular}

Fonte: Aparelho GPS da marca Garmin, modelo WGS84. 


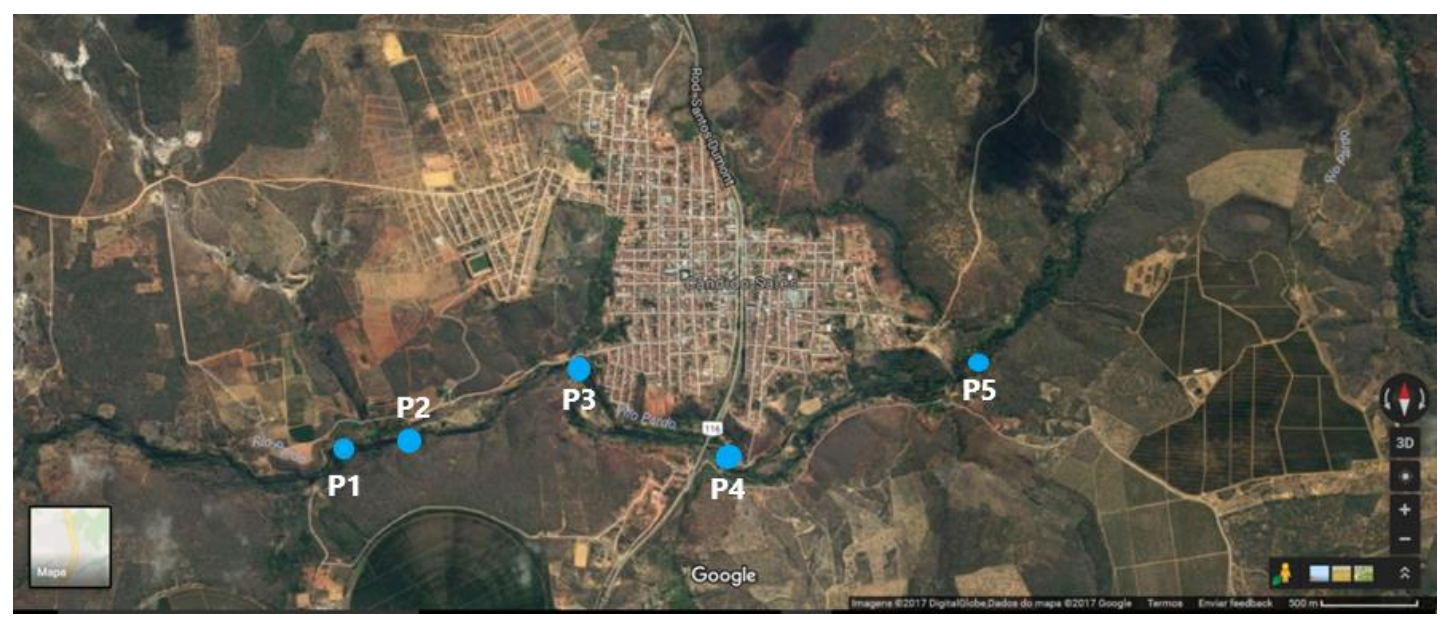

Figura 2: Foto de Satélite de Cândido Sales - BA, com as marcações dos pontos de coleta (P1 ao P5).**

\section{Procedimento de Coleta de Amostras de Água}

As amostras de água destinadas aos estudos foram coletadas seguindo a metodologia apresentada no Manual da Embrapa de Procedimento de amostragem e análise físico-química de água:

Foram coletadas amostras em triplicata para cada ponto de coleta (P1, P2, P3, P4 e P5);

$\checkmark$ As amostras foram coletadas em frascos de Polietileno Tereftalato (PET) de 500 $\mathrm{ml}$, lacradas. Em seguida a água original foi descartada e a embalagem novamente fechada;

$\checkmark$ Removeu-se a tampa do frasco, em seguida, seguro pela base inferior e virou-se com a boca para baixo. Mantendo-o nessa posição, foi mergulhado na água rapidamente, a uma profundidade de 15 a $30 \mathrm{~cm}$. Essa técnica evitou a entrada de contaminantes da superfície da água;

$\checkmark$ Com o frasco submerso, virou-se para linha horizontal no sentido contrário a correnteza;

$\checkmark$ Lentamente o frasco foi inclinado, fazendo com que a boca fique voltada para cima, fazendo que o ar interno do recipiente saia e por consequência, o enchimento com água. Tendo o cuidado de não coletar partículas ou resíduos estranhos que não compõem a constituição natural da água;

Trazendo o frasco à superfície, foi desprezada a água e repetiu-se o mesmo processo num total de 3 (três) vezes. Essa técnica serve para ambientar o frasco com as condições da água do rio, evitando que resíduos da água mineral que estava contida no frasco interfira nas análises.

$\checkmark$ Depois de coletar, vedar com tampa própria, secar e identificar, foram acondicionados em uma caixa de isopor ou bolsa térmica (sem gelo) para manter sua temperatura ambientada. 
As amostras foram transportadas até uma geladeira (não congelar) e dispostas em uma parte onde não foram remanejadas ou movidas até o dia seguinte, quando foram novamente colocadas na caixa de isopor ou bolsa térmica e transportada imediatamente para o Laboratório de Química da Faculdade Independente do Nordeste (FAINOR), situada na Avenida Luiz Eduardo Magalhães, 1035, Bairro Candeias, no município de Vitória da Conquista - BA. Ao chegar ao Laboratório, as amostras foram transferidas do recipiente de transporte para a geladeira ou equivalente, contanto que se mantenha refrigerados (não congelados) até o momento da análise.

Já no laboratório, estiveram disponíveis frascos de Béquer devidamente esterilizados, identificados e em quantidade disponível suficiente para cada amostra.

Para analisar a qualidade da água, serão realizados testes de parâmetros físico-químicos com seus respectivos aparelhos: Condutividade elétrica (Condutivímetro); $\mathrm{pH}$ (pHmetro); Resistividade elétrica (Condutivímetro); Temperatura $\left({ }^{\circ} \mathrm{C}\right)$; TDS ((teor de sólidos dissolvidos) Condutivímetro com Medidor de TDS); Turbidez (Turbidímetro). Os ensaios de dureza total e teor de cloreto foram realizados com vidraria adequada de acordo suas metodologias.

Todos os equipamentos foram ser previamente calibrados para minimizar os erros de aferição dos parâmetros.

As amostras de água dos frascos foram então transferidas em quantidade suficiente para o respectivo Béquer e logo depois feitas as análises nos equipamentos correspondentes, sempre seguindo as instruções formuladas de acordo o fabricante.

Para a determinação do teor de Cloreto, foi utilizado Método de Mohr, utilizando técnicas de titulação com solução de Nitrato de Prata para determinar a quantidade de íons cloreto presentes na amostra.

\section{Análise Estatística}

As amostras coletadas foram analisadas em laboratório e geraram os valores dos dados correspondentes a cada parâmetro físico-químico. Esses valores foram posteriormente comparados com as legislações vigentes para cada parâmetro obtido onde os resultados indicaram se a água está apta ao consumo humano.

Foram realizados cálculos de dispersão baseados no coeficiente de variação e desvio padrão, para avaliar os dados coletados pelas análises das amostras.

Os valores obtidos foram referencialmente comparados com as legislações vigentes:

- DECRETO-LEI na 306/2007 - "Estabelece o regime da qualidade da água destinada ao consumo humano.". 
- PORTARIA no 1469/2000 - "Estabelece os procedimentos e responsabilidades relativos ao controle e vigilância da qualidade da água para consumo humano e seu padrão de potabilidade, e dá outras providências.".

- PORTARIA MS no 2.914/2011 - "Dispõe sobre os procedimentos de controle e de vigilância da qualidade da água para consumo humano e seu padrão de potabilidade.".

- Resolução CONAMA no 430/2011 - "Dispõe sobre as condições e padrões de lançamento de efluentes, complementa e altera a Resolução no 357, de 17 de março de 2005, do Conselho Nacional do Meio Ambiente-CONAMA."

- Resolução CONAMA no 397, de 3 de abril de 2008 - "Altera o inciso II do § 4o e a Tabela X do $\$ 5^{\circ}$, ambos do art. 34 da Resolução do Conselho Nacional do Meio AmbienteCONAMA n $n^{\circ} 357$, de 2005."

- Resolução CONAMA no 357/2005 - "Dispõe sobre a classificação dos corpos de água e diretrizes ambientais para o seu enquadramento, bem como estabelece as condições e padrões de lançamento de efluentes, e dá outras providências."

- Resolução CONAMA n 20/1986 - "Estabelece classificação das águas, doces, salobras e salinas do Território Nacional."

\section{Resultados}

\section{Parâmetros Físico-Quimicos}

Tabela 2: valores dos parâmetros físico-químicos - $1^{\text {a }}$ Análise

\begin{tabular}{l|c|c|c|c|c|c}
\hline \multirow{2}{*}{ Parâmetro } & \multicolumn{5}{|c|}{ Amostras dos pontos } & \multirow{2}{*}{ Valores de referência } \\
\cline { 2 - 6 } & $\mathbf{P 1}$ & $\mathbf{P 2}$ & $\mathbf{P 3}$ & $\mathbf{P 4}$ & $\mathbf{P 5}$ & \\
\hline $\begin{array}{l}\text { Condutividade } \\
\text { elétrica }\end{array}$ & 90,9 & 95,13 & 148,6 & 166,8 & 173,43 & $10,0-100,00 \mu \mathrm{S} / \mathrm{cm}$ \\
\hline $\begin{array}{l}\text { pH (fita) } \\
\text { Temp. }\left({ }^{\circ} \mathbf{C}\right)\end{array}$ & $\begin{array}{c}6,0 \\
20^{\circ} \mathrm{C}\end{array}$ & $\begin{array}{c}6,5 \\
24^{\circ} \mathrm{C}\end{array}$ & $\begin{array}{c}5,0 \\
25^{\circ} \mathrm{C}\end{array}$ & $\begin{array}{c}5,5 \\
24^{\circ} \mathrm{C}\end{array}$ & $\begin{array}{c}5,5 \\
21^{\circ} \mathrm{C}\end{array}$ & $5,0-9,0$ \\
\hline $\begin{array}{l}\text { pH (pHmetro) } \\
\text { Temp. }\left({ }^{\circ} \mathbf{C}\right)\end{array}$ & $\begin{array}{c}6,53 \\
23^{\circ} \mathrm{C}\end{array}$ & $\begin{array}{c}6,16 \\
23^{\circ} \mathrm{C}\end{array}$ & $\begin{array}{c}7,25 \\
23^{\circ} \mathrm{C}\end{array}$ & $\begin{array}{c}6,97 \\
23^{\circ} \mathrm{C}\end{array}$ & $\begin{array}{c}6,72 \\
23^{\circ} \mathrm{C}\end{array}$ & $5,0-9,0$ \\
\hline $\begin{array}{l}\text { Resistividade } \\
\text { elétrica }\end{array}$ & $11,13 \mathrm{k}$ & $10,63 \mathrm{k}$ & $6,8 \mathrm{k}$ & $6,2 \mathrm{k}$ & $5,9 \mathrm{k}$ & $2 \times 10^{1}-2 \times 10^{3} \Omega \mathrm{m}$ \\
\hline TDS & 45,26 & 48,26 & 74,36 & 83,20 & 87,00 & $500,00 \mathrm{mg} / \mathrm{L}$ \\
\hline Turbidez & 1,90 & 2,88 & 5,69 & 2,16 & 1,92 & $40,0 \mathrm{FTU}$ \\
\hline
\end{tabular}

Fonte: Pesquisa dos autores, 2018. 
Tabela 3: valores dos parâmetros físico-químicos $-2^{\mathrm{a}}$ Análise

\begin{tabular}{l|c|c|c|c|c|c}
\hline \multirow{2}{*}{ Parâmetro } & \multicolumn{5}{|c|}{ Amostras dos pontos } & \multirow{2}{*}{$\begin{array}{c}\text { Valores de } \\
\text { referência }\end{array}$} \\
\cline { 2 - 6 } & $\mathbf{P 1}$ & $\mathbf{P 2}$ & $\mathbf{P 3}$ & $\mathbf{P 4}$ & $\mathbf{P 5}$ & \\
\hline $\begin{array}{l}\text { Condutividade } \\
\text { elétrica }\end{array}$ & 100,1 & 145,86 & 335,0 & 484,0 & 411,0 & $10,0-100,00 \mu \mathrm{S} / \mathrm{cm}$ \\
\hline $\begin{array}{l}\text { pH (fita) } \\
\text { Temp. }{ }^{\circ} \mathbf{C}\end{array}$ & $\begin{array}{c}6,0 \\
20,0^{\circ} \mathrm{C}\end{array}$ & $\begin{array}{c}6,0 \\
24,0^{\circ} \mathrm{C}\end{array}$ & $\begin{array}{c}6,0 \\
25,0^{\circ} \mathrm{C}\end{array}$ & $\begin{array}{c}6,0 \\
24,0^{\circ} \mathrm{C}\end{array}$ & $\begin{array}{c}6,0 \\
21,0^{\circ} \mathrm{C}\end{array}$ & $5,0-9,0$ \\
\hline $\begin{array}{l}\text { pH (pHmetro) } \\
\text { Temp. }{ }^{\circ} \mathbf{C}\end{array}$ & 6,49 & 6,01 & 7,37 & 6,82 & 6,83 & $5,0-9,0$ \\
\hline $\begin{array}{l}\text { Resistividade } \\
\text { elétrica }\end{array}$ & $11,0 \mathrm{k}$ & $7,56 \mathrm{k}$ & 3307,33 & 2296,66 & 2709,0 & $2 \times 10^{1}-2 \times 10^{3} \Omega \mathrm{m}$ \\
\hline TDS & 45,3 & 65,56 & 146,67 & 213,0 & 182,0 & $500,00 \mathrm{mg} / \mathrm{L}$ \\
\hline Turbidez & 2,24 & 7,30 & 3,13 & 2,50 & 1,32 & $40,0 \mathrm{FTU}$ \\
\hline
\end{tabular}

Fonte: Pesquisa dos autores, 2018.

Tabela 4: valores dos parâmetros físico-químicos - $3^{\text {a }}$ Análise

\begin{tabular}{l|c|c|c|c|c|c}
\hline \multirow{2}{*}{ Parâmetro } & \multicolumn{5}{|c|}{ Amostras dos pontos } & \multirow{2}{*}{$\begin{array}{c}\text { Valores de } \\
\text { referência }\end{array}$} \\
\cline { 2 - 6 } & $\mathbf{P 1}$ & $\mathbf{P 2}$ & $\mathbf{P 3}$ & $\mathbf{P 4}$ & $\mathbf{P 5}$ & \\
\hline $\begin{array}{l}\text { Condutividade } \\
\text { elétrica }\end{array}$ & 92,23 & 96,1 & 104,53 & 132,20 & 224,0 & $10,0-100,00 \mu \mathrm{S} / \mathrm{cm}$ \\
\hline $\begin{array}{l}\text { pH (fita) } \\
\text { Temp. }{ }^{{ }^{\mathbf{C}}}\end{array}$ & $\begin{array}{c}6,0 \\
23^{\circ} \mathrm{C}\end{array}$ & $\begin{array}{c}6,5 \\
24^{\circ} \mathrm{C}\end{array}$ & $\begin{array}{c}5,0 \\
25^{\circ} \mathrm{C}\end{array}$ & $\begin{array}{c}5,5 \\
24^{\circ} \mathrm{C}\end{array}$ & $\begin{array}{c}5,5 \\
22^{\circ} \mathrm{C}\end{array}$ & $5,0-9,0$ \\
\hline $\begin{array}{l}\text { pH (pHmetro) } \\
\text { Temp. }{ }^{\circ} \mathbf{C}\end{array}$ & $\begin{array}{c}7,15 \\
23,9^{\circ} \mathrm{C}\end{array}$ & $\begin{array}{c}7,07 \\
23,47^{\circ} \mathrm{C}\end{array}$ & $\begin{array}{c}7,42 \\
23,13^{\circ} \mathrm{C}\end{array}$ & $\begin{array}{c}7,17 \\
23,13^{\circ} \mathrm{C}\end{array}$ & $\begin{array}{c}7,25 \\
23,50^{\circ} \mathrm{C}\end{array}$ & $5,0-9,0$ \\
\hline $\begin{array}{l}\text { Resistividade } \\
\text { elétrica }\end{array}$ & $11,0 \mathrm{k}$ & $10,66 \mathrm{k}$ & $9,6 \mathrm{k}$ & $7,53 \mathrm{k}$ & 4606,66 & $2 \times 10^{1}-2 \times 10^{3} \Omega \mathrm{m}$ \\
\hline TDS & 44,07 & 45,53 & 51,97 & 65,73 & 109,7 & $500,00 \mathrm{mg} / \mathrm{L}$ \\
\hline Turbidez & 2,22 & 4,51 & 2,52 & 2,86 & 2,69 & $40,0 \mathrm{FTU}$ \\
\hline
\end{tabular}

Fonte: Pesquisa dos autores, 2018.

\section{Dureza Total}

Para determinar o valor da dureza total da amostra, segue-se: 


$$
\text { DurezaTotal }=\frac{\text { V.M.100.000 }}{\mathrm{A}}\left(\mathrm{mgCaCO}_{3} / \mathrm{L}\right)
$$

$\mathrm{V}=$ volume da solução padrão de EDTA gasto na titulação da amostra $(\mathrm{mL})$

$\mathrm{M}=$ Molaridade da solução de EDTA (M)

$\mathrm{A}=$ volume da amostra tomada para análise $(\mathrm{mL})$

Tabela 5: Valores medidos de dureza total

\begin{tabular}{c|c|c}
\hline & Período seco & Período chuvoso \\
\hline P1 & $20 \mathrm{mg} / \mathrm{L}$ & $24 \mathrm{mg} / \mathrm{L}$ \\
\hline $\mathbf{P 2}$ & $20 \mathrm{mg} / \mathrm{L}$ & $25 \mathrm{mg} / \mathrm{L}$ \\
\hline $\mathbf{P 3}$ & $19 \mathrm{mg} / \mathrm{L}$ & $25 \mathrm{mg} / \mathrm{L}$ \\
\hline $\mathbf{P 4}$ & $38 \mathrm{mg} / \mathrm{L}$ & $52 \mathrm{mg} / \mathrm{L}$ \\
\hline P5 & $45 \mathrm{mg} / \mathrm{L}$ & $60 \mathrm{mg} / \mathrm{L}$ \\
\hline
\end{tabular}

Fonte: Pesquisa dos autores, 2018.

\section{Teor de Cloreto}

Para realizar os cálculos de concentração do cloreto, a molaridade da solução de nitrato de prata foi calculada da seguinte forma:

$$
M=\frac{m}{V \cdot M M}
$$

Pela relação estequiométrica, temos que o número de mol do nitrato de prata é igual ao do cloreto de sódio utilizado, a fim de encontrar a concentração de cloreto presente, podemos escrever que:

$$
C_{C l}=\frac{M_{\mathrm{AgNO}_{3}} \cdot V_{\mathrm{AgNO} 3} \cdot M M_{C l}}{V_{\text {amostra }}}
$$

Sendo $\mathrm{V}_{\mathrm{AgNO}}$ o volume médio de nitrato de prata utilizado na titulação e $\mathrm{M}_{\mathrm{AgNO} O}$ a molaridade do nitrato de prata encontrado.

Sendo assim, a Tabela 6 apresenta os seguintes resultados encontrados nas análises: 
Tabela 6: Valores medidos do teor de cloreto

\begin{tabular}{c|c}
\hline Período seco & Período chuvoso \\
\hline Concentração de $\mathbf{C l}^{-}$ & ${\text {Concentração de } \mathbf{C l}^{-}}^{-}$ \\
\hline P1 & $\mathbf{P 1}$ \\
\hline $187,0 \mathrm{~g} / \mathrm{L}$ & $\mathbf{P 2}$ \\
\hline $\mathbf{P 2}$ & $216,2 \mathrm{~g} / \mathrm{L}$ \\
\hline $192,8 \mathrm{~g} / \mathrm{L}$ & $\mathbf{P 3}$ \\
\hline $\mathbf{P 3}$ & $204,5 \mathrm{~g} / \mathrm{L}$ \\
\hline $187,0 \mathrm{~g}] \mathrm{L}$ & $\mathbf{P 4}$ \\
\hline $\mathbf{P 4}$ & $239,6 \mathrm{~g} / \mathrm{L}$ \\
\hline $216,2 \mathrm{~g} / \mathrm{L}$ & $\mathbf{P 5}$ \\
\hline $\mathbf{P 5}$ & $292,2 \mathrm{~g} / \mathrm{L}$ \\
\hline $263,0 \mathrm{~g} / \mathrm{L}$ &
\end{tabular}

\section{Discussão}

As coletas das amostras de água foram realizadas durante os meses de agosto e outubro, devido à variação de precipitação pluvial da região, que varia do mês mais seco (agosto) até o início dos meses de maior chuva, que iniciam em outubro e vão até janeiro. O objetivo dessa margem de análise é verificar se há variação considerável dos parâmetros físico-químicos analisados e se essas mudanças podem ocasionar riscos à saúde dos moradores que consomem a água diretamente do rio.

As amostras foram coletadas em 5 (cinco) pontos específicos do curso do Rio Pardo, denominados de P1 a P5.

P1 (Aproximadamente 300 metros do P2): Essa é uma área onde há pouco ou nenhum contato humano com a água, por se tratar de local menos atraente para banhistas e não haver moradores que consumiriam desse corpo d'agua, é considerado local ideal para coleta devido essa ausência específica de interferentes em questão. 


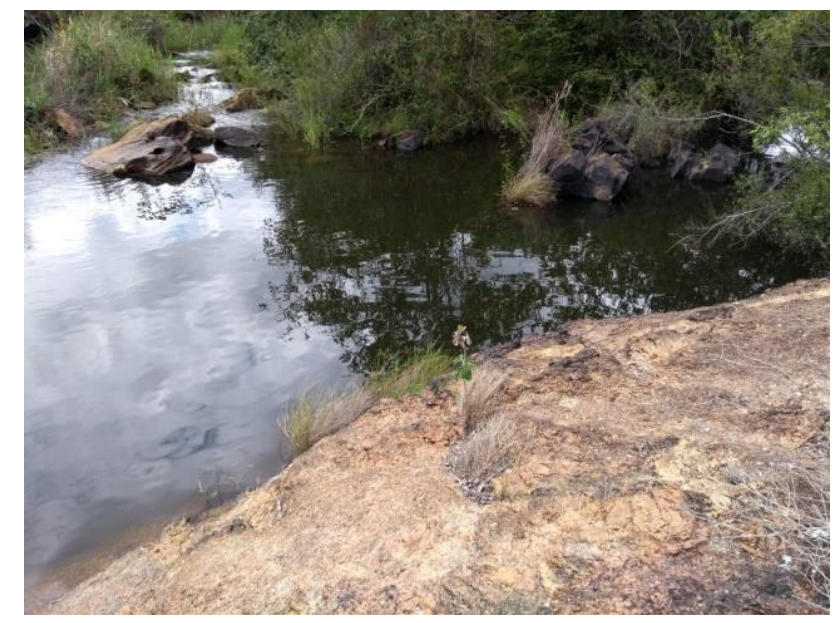

Figura 3: Ponto de coleta 1 (P1)

P2 (Local de captação de água da Embasa): Nesse ponto se encontra o motor de extração de água que direciona por meio de tubulação, a água que será tratada pela Embasa e logo depois distribuída para os moradores do município de Cândido Sales. O local é cercado e protegido, por isso não há consumo da água por pessoas ou animais. Entretanto, subindo o leito do rio, encontra-se uma fazenda, onde os moradores utilizam a água do rio para consumo sem o devido tratamento, apesar de aparentemente não haver descarte de poluentes no local.

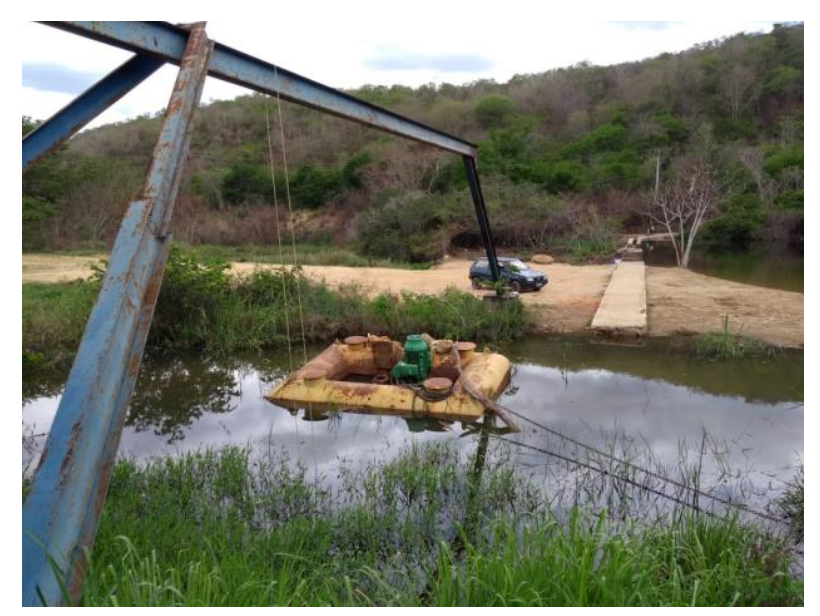

Figura 4: Ponto de coleta $2(\mathrm{P} 2)$

P3 (Menos de 100 metros até o início das residências): Nesse ponto, algumas pessoas utilizam o rio para banho recreativo. O esgoto doméstico é descartado por tubulação e é escoado para o rio, como visto na Figura 4. 


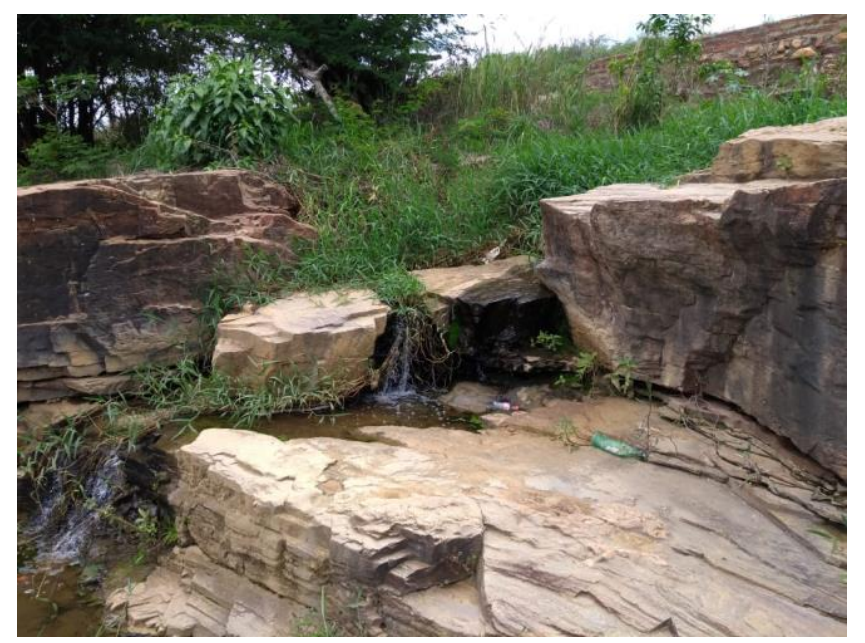

Figura 5: Esgoto residencial descartado para o leito do rio

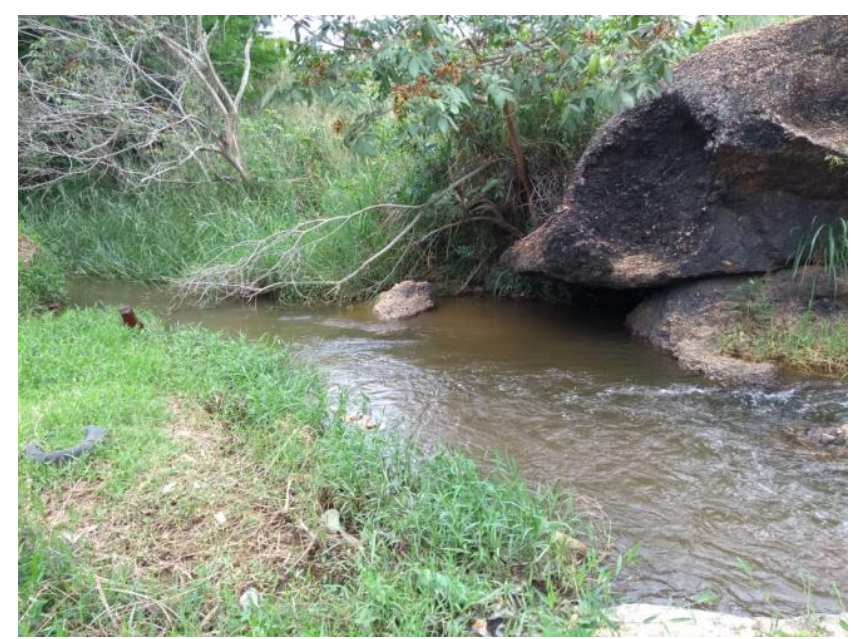

Figura 6: Ponto de coleta 3 (P3)

\section{P4 (Local onde os moradores usam a água para consumo, banho e outras atividades}

de limpeza): Nessa área os moradores usam a água tanto para consumo e banho, quanto para lavagem de roupa e em alguns casos, até a lavagem de veículos.

Como pode ser visto na figura 8 , o local é alvo dos esgotamentos domésticos que provém da cidade e descartado diretamente no rio. 


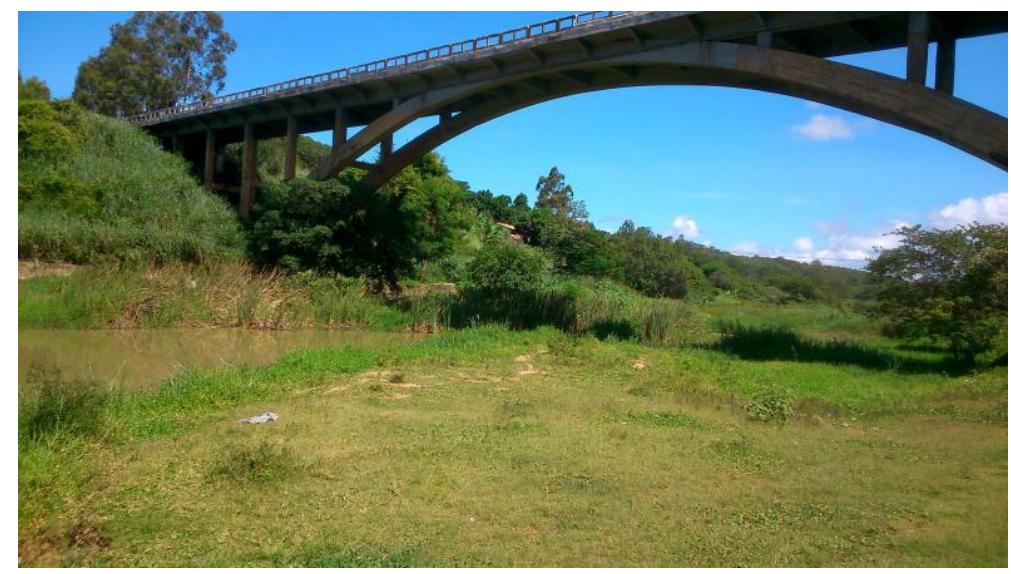

Figura 7: Ponte sobre o Rio Pardo

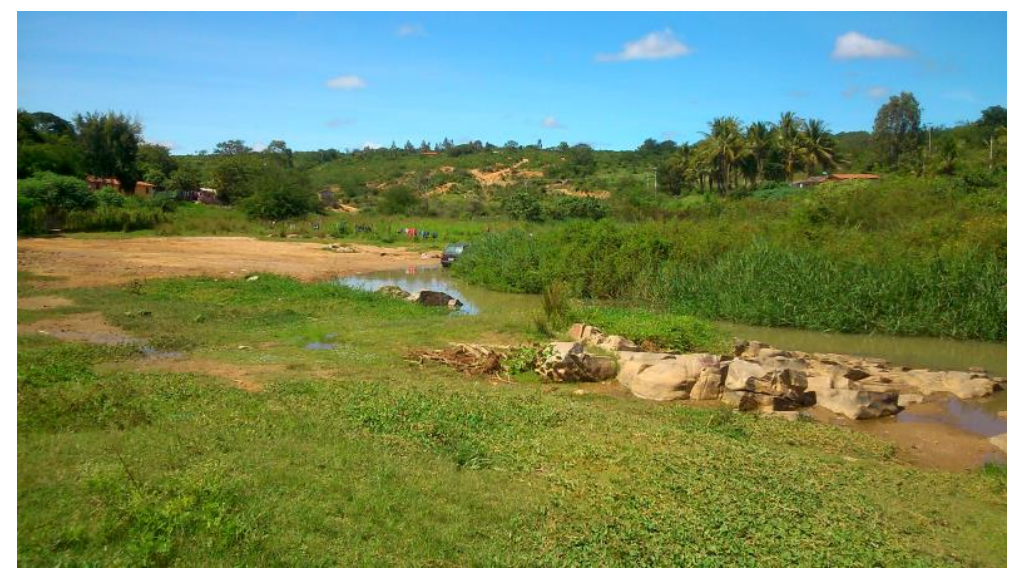

Figura 8: Ponto de Coleta 4 (P4)

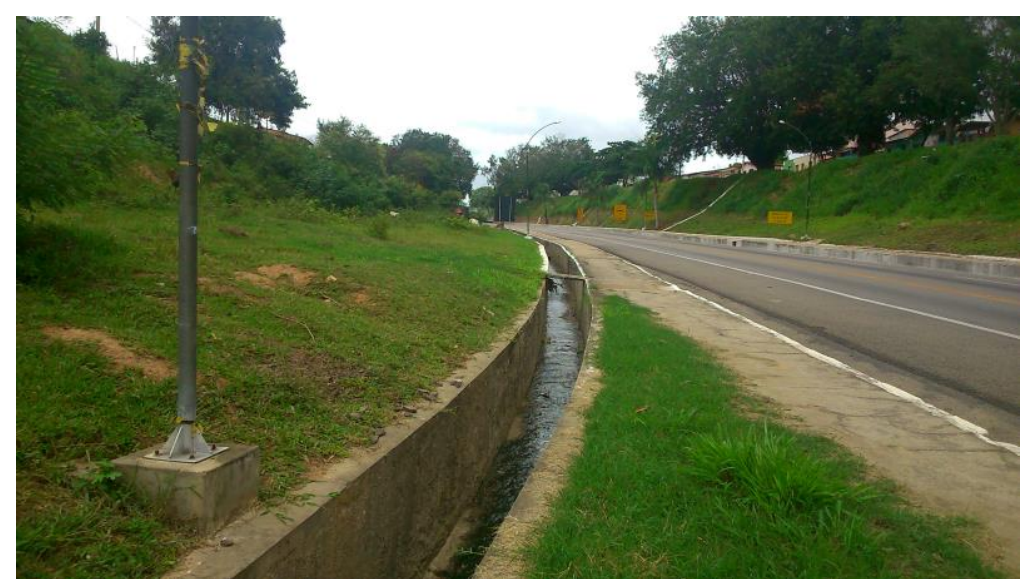

Figura 9: Descarte de esgoto doméstico 


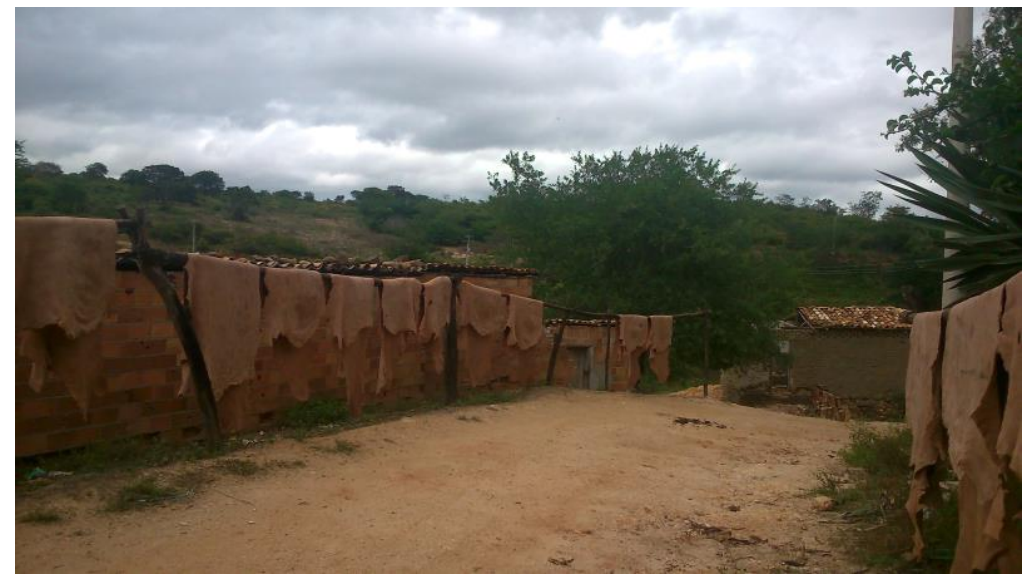

Figura 10: Curtume prepara peles de animais (entre P4 e P5)

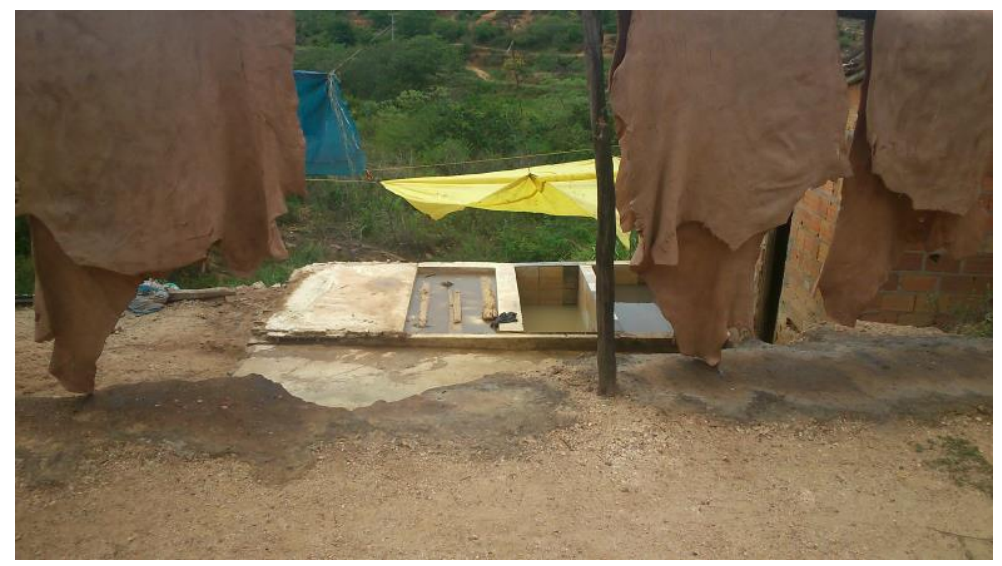

Figura 11: Tanque de processamento onde são aplicados os produtos de limpeza e posteriormente a água residual é descartada nas águas do Rio Pardo.

P5 (último ponto acessível abaixo de onde o esgoto é descartado): Esse ponto do leito do rio se encontra a um nível abaixo dos outros pontos de coleta. Nessa área será comparada se a água ainda é influenciada pelos poluentes acima, ao mesmo tempo, comparar a integridade da água em relação ao ponto de captação da Embasa. 


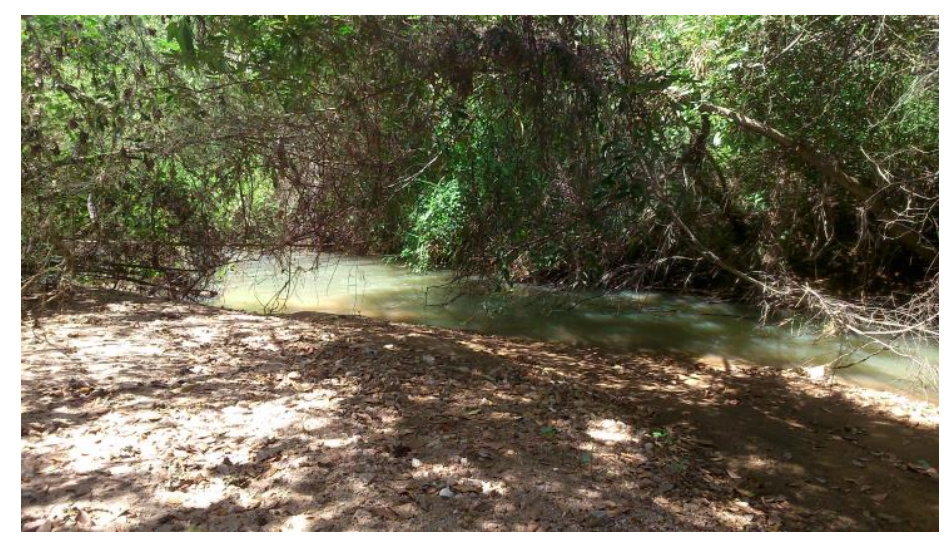

Figura 12: Ponto de Coleta 5 (P5)

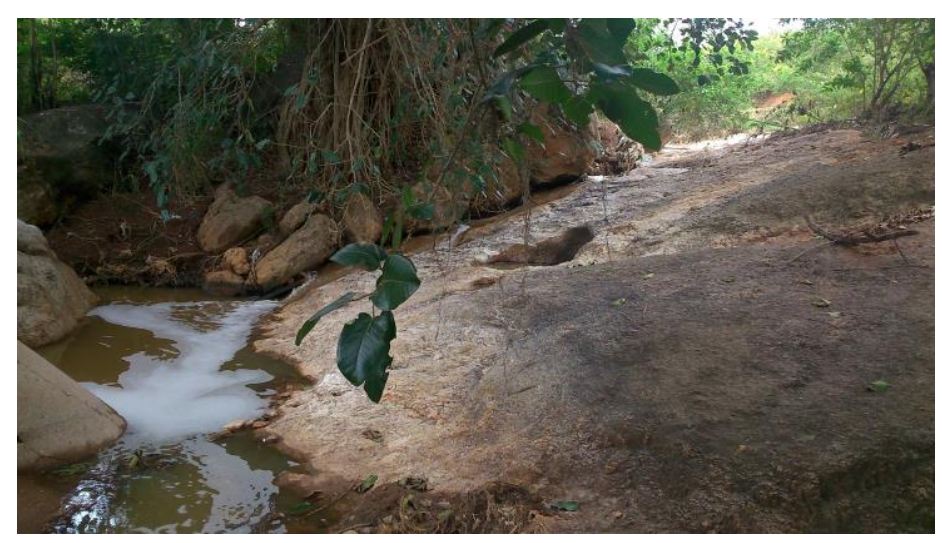

Figura 13: Seguindo para o P5. Nota-se presença de poluentes das residências acima na água.

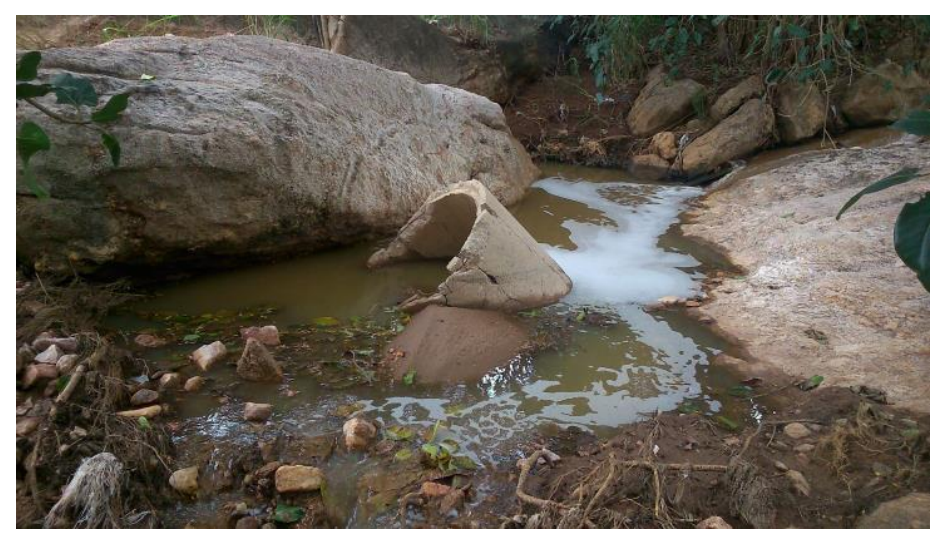

Figura 14: Formação de espuma devido o provável descarte de detergentes.

Levando em consideração o conceitual de Santos (2007), quando diz que, quanto maior a condutividade elétrica, maior a contaminação da água, pode-se observar que os valores de P3, P4 e P5, se encontram acima do valor referenciado pela Resolução CONAMA no 357 de 2005. E apesar dos valores de P1 e P2 se encontrarem dentro da margem tolerável, seus valores se aproximam do limite 
superior, que seria de $100 \mu \mathrm{S} / \mathrm{cm}$. Em uma escala comparativa, percebe-se uma ascendência nos valores medidos, de acordo segue-se o leito do rio.

Os valores de Condutividade elétrica se tornam mais evidentes na segunda análise, quando por sinal, a precipitação pluvial da região se encontra em sua época mais escassa e a temperatura ambiente se eleva. Essa hipótese é considerada por Santos (2007) quando afirma sobre o potencial da água em dissolver as substâncias presentes na água. Na terceira análise observa-se que os valores voltam a se nivelar com aqueles das amostras coletadas entre os meses de agosto e setembro ( $1^{\mathrm{a}}$ análise).

Segundo as análises realizadas, os valores de pH, Resistividade elétrica, TDS e Turbidez se encontram dentro dos parâmetros exigidos pela legislação vigente. Não apresentando variações consideráveis entre as amostras.

Tanto a Dureza Total, quanto o Teor de Cloreto, foram comparadas apenas entre a $1^{\mathrm{a}}$ e $3^{\mathrm{a}}$ amostra, para verificar a probabilidade de variação desses parâmetros apresentam alterações devido o nível de variação da precipitação pluvial entre o mês de Agosto em relação ao mês de Outubro (Ver tabela 1).

A Dureza total apresenta valores dentro do padrão exigido pela Portaria $n^{\circ} 518 / 2004$ do Ministério da Saúde, que determina uma concentração máxima de cálcio é $500 \mathrm{mg} / \mathrm{L}$ permitido para água para consumo humano.

No método de Mohr o pH da solução a ser titulada deve estar entre 6,5 e 10,5. Se o pH de uma solução a ser testada estiver inferior a 6,5 o nível de íons cromato de prata fica muito reduzida de tal ordem que o produto de solubilidade do cromato de prata só é atingido com uma concentração maior de íons Ag++, o que aumenta o volume da titulação. Se o pH da solução estiver acima de 10,5, a solução se comportará de forma a precipitar o hidróxido de prata e roubando íons Ag+ que precipitaria a prata como Ag2CrO4. O efeito também irá aumentar o consumo volumétrico da solução de AgNO3 para precipitar o indicador. (CRUZ; CLAIN, 2010)

As amostras que apresentaram $\mathrm{pH}$ abaixo de 6,5 foram corrigidas com solução de $\mathrm{NaCl}$ a 0,1 mol L $\mathrm{L}^{-1}$ para se adequar à escala exigida pelo método. A Portaria $\mathrm{n}^{\circ} 1.469$ de 29 de dezembro de 2000 , do Ministério da Saúde, determina que o teor máximo de cloreto permissível, em águas de abastecimento, é de $250 \mathrm{mg} / \mathrm{L}$ de $\mathrm{Cl}^{-}$.

\section{Conclusões}

As análises constataram que esses valores se encontram em uma margem ainda segura para o consumo humano, mas pode-se observar que no Ponto 5 (P5) de coleta, esses valores superam o recomendado pelo Ministério da Saúde. E ainda percebe-se elevação desse teor em todos os pontos de coleta quando os níveis de chuva estavam aumentados, constatando a provável erosão do solo de margem. 
Devido o aumento do teor de cloro, quando os níveis de chuva estavam aumentando, possivelmente pela erosão das margens, carregadas pela chuva, cabe-se a avaliação do solo, com o objetivo de rastrear se a origem desse metal é natural do minério da região ou é de intervenção humana, por ocasião de descarte de lixo ou por uso de agrotóxicos em plantações próximas as margens do Rio Pardo.

A ação do cloro no corpo humano causa problemas respiratórios como asma, rinite e reações alérgicas respiratórias, garganta e olhos. Nas crianças, esses quadros podem ser ainda mais agravante devido sua condição fisiológica naturalmente mais sensível. O vapor de água dos chuveiros quentes podem manter essas partículas suspensas, aumentando as chances de contato com pele e mucosas. (NETO, 2014)

Concluímos que, em relação aos parâmetros físico-químicos demonstrados nessa pesquisa, apesar do despejo de sedimentos no rio, a água está apta ao consumo. Sendo ainda necessária uma segunda pesquisa, de solo para comprovação de tal. Apesar da alteração pela precipitação pluvial os dados coletados por essa pesquisa não indicam risco iminente para a população, embora seja necessário um acompanhamento do estado e dos níveis fluviais do rio, já que, é possível perceber que não é mais o mesmo de anos passados.

\section{Referências}

ABREU, Eduardo Lima de. Imageamento de Resistividade Elétrica de Áreas Contaminadas Utilizando Arranjos Poço-Superfície. São Paulo - Brasil, 2012. Disponível em: <http://www.iag.usp.br/pos/sites/default/files/d_eduardo_1_abreu_corrigida.pdf >. Acesso em 10 mai. 2017;

BACCAN, Nivaldo et.al. Química analítica quantitativa elementar. 3 ed. São Paulo: Blucher - Instituto Mauá de tecnologia, 2001;

BACELLAR, Luís de Almeida Prado; MORAIS, Fernando. Geofísica Aplicada ao Estudo de Fluxos da Água no Solo. Uberlândia - MG, 2010. Disponível em: <http://repositorio.ufop.br/bitstream/123456789/4058/1/ARTIGO_Geof\%C3\%ADsicaAplicada Estudo.pdf > Acesso em 11 mai. 2017;

Bacia do Rio Pardo. Disponível em: <http://www.cemig.com.br/ptbr/A_Cemig_e_o_Futuro/sustentabilidade/nossos_programas/ambientais/peixe_vivo/Paginas/rio _pardo.aspx> Acesso em 19 abr. 2017;

BERTOSSI, Ana Paula Almeida et al. Qualidade da água em microbacias hidrográficas com diferentes coberturas do solo no sul do Espírito Santo. Rev. Árvore, Viçosa, v. 37, n. 1, p. 107117, fev. 2013. Disponível em: <http://www.scielo.br/scielo.php?script=sci_arttext\&pid=S0100$67622013000100012 \& \operatorname{lng}=$ pt\&nrm=iso $>$. Acesso em 07 fev. 2017;

BRASIL. Decreto-lei $\mathbf{n}^{\mathbf{0}}$ 306/2007 de 27 de agosto, relativo ao controle da qualidade da água destinada ao consumo humano. Disponível em: <http://www.iasaude.pt/attachments /article/659/DL\%20306-2007.pdf> Acesso em 21 nov. 2018; 
BRASIL. Legislação básica. / Agência Nacional de Águas. - 2. ed. - Brasília: ANA, 2007. Disponível em: <http://www.cbcs.org.br/userfiles/download/LIVROAGENCIANACIONAL DEAGUAScd_LB2.pdf> Acesso em 12 mai. 2017;

BRASIL. Lei $\mathbf{n}^{\mathbf{0}}$ 8.080, de 19 de setembro de 1990. Dispõe sobre as condições para a promoção, proteção e recuperação da saúde, a organização e o funcionamento dos serviços correspondentes e dá outras providências. Diário Oficial da União 1990; 20 set. Disponível em: <http://www2.camara.leg.br/legin/fed/lei/1990/lei-8080-19-setembro-1990-365093normaatualizada-pl.pdf > . Acesso em 09 mai. 2017;

BRASIL. MINISTÉRIO DA SAÚDE. Portaria no 518, de 25 de março de 2004. Estabelece os procedimentos e responsabilidades relativos ao controle e vigilância da qualidade da água para consumo humano e seu padrão de potabilidade, e dá outras providências. Diário Oficial da União, Brasília, 2004. Disponível em: < http://bvsms.saude.gov.br/bvs/publicacoes/portaria _518_2004.pdf>. Acesso em 28 abr. 2017;

BRASIL. MINISTÉRIO DA SAÚDE. - Portaria no 1469, de 29 de dezembro de 2000. Estabelece os procedimentos e responsabilidades relativos ao controle e vigilância da qualidade da água para consumo humano e seu padrão de potabilidade, e dá outras providências. Diário Oficial da União, Brasília, 2000. Disponível em: <http://bvsms.saude.gov.br/bvs /saudelegis/gm/2011/prt2914_12_12_2011.html> Acesso em 20 nov. 2018;

BRASIL. Panorama da qualidade das águas superficiais do Brasil: 2012/Agência Nacional de Águas - Brasília: ANA, 2012. Disponível em: <http://arquivos.ana.gov.br/imprensa/ publicacoes/Panorama_Qualidade_Aguas_Superficiais_BR_2012.pdf $>$ Acesso em 12 mai. 2017;

BRASIL. Portaria MS No 2914 de 12 dez. 2011. Dispõe sobre os procedimentos de controle e de vigilância da qualidade da água para consumo humano e seu padrão de potabilidade. Disponível em: http://www.comitepcj.sp.gov.br/download/Portaria_MS_2914-11.pdf > Acesso em 12 mai. 2017;

Clima: Cândido Sales. Disponível em: <https://pt.climate-data.org/location/43274/>_Acesso em 18 abr. 2017;

CONAMA - Conselho Nacional do Meio-Ambiente. Resolução no $\mathbf{3 5 7}$ de 17 de março de 2005. Dispõe sobre a classificação dos corpos de água e diretrizes ambientais para o seu enquadramento, bem como estabelece as condições e padrões de lançamento de efluentes, e dá outras providências. Publicação Diário Oficial da União, Poder Executivo, Brasília, DF, n.87, p.44, 2005. Disponível em: <http://licenciamento.cetesb.sp.gov.br/legislacao/federal/resolucoes/2005_Res_CONAMA _357.pdf > Acesso em 04 mai. 2017;

CONAMA - Conselho Nacional do Meio-Ambiente. Resolução no 430, de 13 de maio de 2011. Dispõe sobre as condições e padrões de lançamento de efluentes, complementa e altera a Resolução no 357, de 17 de março de 2005, do Conselho Nacional do Meio Ambiente-CONAMA. Publicada no DOU $\mathrm{n}^{\circ}$ 92, de 16/05/2011, pág. 89. Disponível em: $<$ https://www.tratamentodeagua.com.br/artigo/resolucao-conama-430-de-13-de-maio-de-2011padroes-de-lancamento-de-efluentes/> Acesso em 06 mai. 2017;

CRUZ, Juliana Nogueira da; CLAIN, Almir Faria. A Interferência do pH na análise de cloreto pelo método de Mohr. Revista eletrônica TECCEN, Vassouras, v. 3, n. 3, p. 29-44, jul./set., 2010. Disponível em: <editora.universidadedevassouras.edu.br/index.php/TECCEN /article/download/255/203 >. Acesso em 20 nov. 2018; 
CUNHA, Helenilza Ferreira Albuquerque et al. Qualidade físico-química e microbiológica de água mineral e padrões da legislação. Rev. Ambient. Água, Taubaté, v. 7, n. 3, p. 155-165, Dec. 2012. Disponível em: <http://www.scielo.br/scielo.php?script=sci_arttext\&pid=S1980993X2012000300013\&lng=en\&nrm=iso>. Acesso em 22 fev. 2017. http://dx.doi.org/10.4136/ambi-agua.908;

DANELUZ, Débora; TESSARO, Dinéia. Padrão físico-químico e microbiológico da água de nascentes e poços rasos de propriedades rurais da região sudoeste do Paraná. Arq. Inst. Biol., São Paulo, v. 82, p. 1-5, 2015. Disponível em: <http://www.scielo.br/scielo.php?script $=$ sci_arttext\&pid=S1808-16572015000100301\&lng=en\&nrm=iso >. Acesso em 30 mar. 2017. Epub Apr 07, 2015. http://dx.doi.org/10.1590/1808-1657000072013;

EMBRAPA - Empresa Brasileira de Pesquisa Agropecuária. Manual de procedimento de amostragem e análise físico-química de água [recurso eletrônico] / Lucilia Maria Parron; Daphne Heloisa de Freitas Muniz; Claudia Mara Pereira. - Dados eletrônicos. - Colombo: Embrapa Florestas, 2011. Disponível em: <http://www.cnpf.embrapa.br/publica /seriedoc/edicoes/doc219.pdf> Acesso em 08 mai. 2017;

FABRIS, Izaquel et al. Determinação de cloretos. Universidade do Oeste de Santa Catarina. Xanxerê - $\quad$ SC, 2012. Disponível em: <https://www.ebah.com.br/content/ABAAAfNTsAL/determinacao-cloretos> Acesso em 20 nov. 2018;

FRAZAO, Paulo; PERES, Marco A; CURY, Jaime A. Qualidade da água para consumo humano e concentração de fluoreto. Rev. Saúde Pública, São Paulo, v. 45, n. 5, p. 964-973, out. 2011. Disponível em: <http://www.scielosp.org/scielo.php?script=sci_arttext\&pid=S003489102011000500018\&lng=pt\&nrm=iso>. Acesso em $07 \mathrm{fev} .2017 . \quad$ Epub 22-Jul2011. http://dx.doi.org/10.1590/S003489102011005000046;

IBGE - Instituto Brasileiro de Geografia e Estatística. Cidades da Bahia - Cândido Sales - BA. 2016. Disponível em: <http://cidades.ibge.gov.br/painel/painel.php?codmun=290670> Acesso em 18 abr. 2017;

MEDEIROS, Adaelson Campelo; LIMA, Marcelo de Oliveira; GUIMARAES, Raphael Mendonça. Avaliação da qualidade da água de consumo por comunidades ribeirinhas em áreas de exposição a poluentes urbanos e industriais nos municípios de Abaetetuba e Barcarena no estado do Pará, Brasil. Ciênc. saúde coletiva, Rio de Janeiro, v. 21, n. 3, p. 695-708, Mar. 2016. Disponível em: <http://www.scielosp.org/scielo.php?script=sci_arttext\&pid=S141381232016000300695\&lng=en\&nrm=iso $>$ Acesso em 29 mar. 2017. http://dx.doi.org/10.1590/1413-81232015213.26572015;

MONITORAMENTO DO DESMATAMENTO NOS BIOMAS BRASILEIROS POR SATÉLITE - ACORDO DE COOPERAÇÃO TÉCNICA MMA/IBAMA - Monitoramento do Bioma Mata Atlântica. p. 19 e 31. Brasília - DF 2012. Disponível em: <http://www.mma.gov.br/estruturas/sbf_chm_rbbio/_arquivos/relatorio_tcnico_mata_atlantica_ 2008_2009_72.pdf > Acesso em 20 abr. 2017;

MOTA, S. Preservação e Conservação de Recursos Hídricos. Rio de Janeiro: Associação Brasileira de Engenharia Sanitária e Ambiental - ABES, $2^{a}$ edição, 1995. Disponível em: < https://www.passeidireto.com/arquivo/16958465/livro_

_preservacao_conservacao_e_recuperacao_dos_recursos_naturais_i-1> Acesso em 23 nov. 2018;

MULLER, Thais; GRANADA, Camille Eichelberger; SPEROTTO, Raul Antonio. Qualidade da água de três locais com potenciais fontes de contaminação no Rio Taquari, RS. Rev. Ambient. Água, Taubaté, v. 11, n. 1, p. 75-84, mar. 2016. Disponível em: 
<http://www.scielo.br/scielo.php?script=sci_arttext\&pid=S1980-993X2016000100075\&lng =en\&nrm=iso> . Acesso em 30 mar. 2017. http://dx.doi.org/10.4136/ambi-agua.1789;

OLIVEIRA, Brunna Stefanny Sangel de; CUNHA, Alan Cavalcanti da. Correlação entre qualidade da água e variabilidade da precipitação no sul do Estado do Amapá. Rev. Ambient. Água, Taubaté, v. $\quad 9, \mathrm{n} . \quad 2$, p. 261-275, June 2014. Disponível em: <http://www.scielo.br/scielo.php?script=sci_arttext\&pid=S1980-993X2014000200008\&lng= en\&nrm=iso >. Acesso em 22 fev. 2017. http://dx.doi.org/10.4136/ambi-agua.1287;

PINHEIRO, Adilson et al. Concentrações e cargas de nitrato e fosfato na Bacia do Ribeirão Concórdia, Lontras, SC. Rev. bras. eng. agríc. ambient., Campina Grande, v. 17, n. 1, p. 86-93, jan. 2013. Disponível em: <http://www.scielo.br/scielo.php?script=sci_arttext\&pid=S141543662013000100012\&lng=pt\&nrm=iso>. Acesso em: $07 \mathrm{fev} .2017 . \quad \mathrm{http} / / /$ dx.doi.org/10.1590/S1415-43662013000100012;

Portal Brasil. A importância das regiões hidrográficas do Brasil. Disponível em: <http://www.brasil.gov.br/meio-ambiente/2017/03/entenda-a-importancia-das-regioeshidrograficas-do-brasil> Acesso em 12 mai. 2017;

QUEIROZ, Ana Carolina Lanza et al. Programa Nacional de Vigilância em Saúde Ambiental Relacionada à Qualidade da Água para Consumo Humano (Vigiagua): lacunas entre a formulação do programa e sua implantação na instância municipal. Saúde soc., São Paulo, v. 21, n. 2, p. 465 478, jun. 2012. Disponível em: <http://www.scielo.br/scielo.php? script=sci_arttext\&pid=S010412902012000200019\&lng=pt\&nrm=iso>. Acesso em 07 fev. 2017. http://dx.doi.org/10.1590/S0104-12902012000200019;

SANTOS, Jarbas R. dos. Aspectos físico-químicos e metais pesados na água e sedimento do Rio Verruga no município de Vitória da Conquista - Ba. 2007. Dissertação (Mestrado) - Área de Concentração - Química Analítica. Universidade Estadual do Sudoeste da Bahia. p. 38 e 62. Jequié - BA, 2007. Disponível em: <http://www.dominiopublico.gov.br/ pesquisa/DetalheObraForm.do?select_action=\&co_obra=142026> Acesso em 10 abr. 2017;

SANTOS, Maria Lúcia Pires dos et al. Efeitos dos escoamentos urbanos e rurais na qualidade das águas do córrego verruga em vitória da conquista - Bahia, Brasil. Quím. Nova, São Paulo, v. 31, n. 8,p. 1997-2003, 2008. Disponível em: <http://www.scielo.br/scielo.php? script=sci_arttext\&pid=S010040422008000800016\&lng=en\&nrm=iso>. Acesso em 10 abr.2017 http://dx.doi.org/10.1590/S0100-40422008000800016;

SCORSAFAVA, Maria Anita et al. Avaliação físico-química da qualidade de água de poços e minas destinada ao consumo humano. Rev. Inst. Adolfo Lutz (Impr.), São Paulo, v. 69, n. 2 , 2010. Disponível em: <http://periodicos.ses.sp.bvs.br/scielo.php?script =sci_arttext\&pid=S0073-98552010000200013\&lng=pt\&nrm=iso>. Acesso em 22 fev. 2017;

SILVA, Demetrius D. da et al. Chuvas intensas no Estado da Bahia. Rev. bras. eng. agríc. ambient., Campina Grande, v. 6, n. 2, p. 362-367, 2002. Disponível em: <http://www.scielo.br/scielo.php?script=sci_arttext\&pid=S1415-43662002000200030\&lng =en\&nrm=iso $>$. Acesso em 16 abr. 2017. http://dx.doi.org/10.1590/S1415-43662002000200030;

SIQUEIRA, Gilmar W.; APRILE, Fabio; MIGUEIS, Antônio Miguel. Diagnóstico da qualidade da água do rio Parauapebas (Pará - Brasil). Acta Amaz., Manaus, v. 42, n. 3, p. 413-422, Sept. 2012. Disponível em: <http://www.scielo.br/scielo.php?script=sci_arttext\&pid=S004459672012000300014\&lng=en\&nrm=iso>. Acesso em 30 mar. 2017. http://dx.doi.org/10.1590/S0044-59672012000300014; 
TEIXEIRA, Mariane Mendes. Resistividade elétrica; Brasil Escola. Disponível em: <http://brasilescola.uol.com.br/fisica/resistividade-eletrica.htm>. Acesso em 12 mai. 2017;

TOMAZELA, Danilo P. Monitoramento espacial e temporal de parâmetros físicos, químicos e biológicos da Bacia Hidrográfica do Rio Capivari (norte da Ilha de Santa Catarina) - SC. 2008. Monografia (Bacharel) - Ciências Biológicas. Universidade Federal de Santa Catarina. Florianópolis - SC, 2008. Disponível em: <http://www.limnos.ufsc.br/assets/docs/TCCDANILO.pdf>. Acesso em 22 mai. 2017;

ZUMACH, Rosalene. Enquadramento de curso de água: Rio Itajaí-açu e seus principais afluentes em Blumenau - SC. 2003. Dissertação (Mestrado) - Engenharia Química - Área de Planejamento de Bacias Hidrográficas. Universidade Federal de Santa Catarina. Florianópolis SC, 2003. Disponível em: <https://repositorio.ufsc.br/bitstream/handle/ 123456789/86351/200163.pdf?sequence=1\&isAllowed=y>. Acesso em 22 mai. 2017.

\section{Como citar este artigo (Formato ABNT):}

ALMEIDA, Wadson Rodrigo Ferreira de; SOUZA, Flavio Mendes de. Análise Físico-Química da Qualidade da Água do Rio Pardo no Município de Cândido Sales - BA. Id on Line Rev.Mult. Psic., 2019, vol.13, n.43, p. 353-378. ISSN: 1981-1179.

Recebido: 30/11/2018;

Aceito: 01/12/2018 